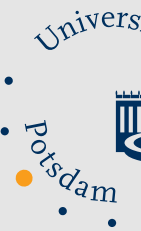

Humanwissenschaftliche Fakultät

Helena Bonache | Rosaura Gonzalez-Mendez | Barbara Krahé

\title{
Adult Attachment Styles, Destructive Conflict Resolution, and the Experience of Intimate Partner Violence
}

Suggested citation referring to the original publication: Journal of Interpersonal Violence (2016) DOI https://doi.org/10.1177/0886260516640776 ISSN (print) 0886-2605

ISSN (online) 1552-6518

Postprint archived at the Institutional Repository of the Potsdam University in: Postprints der Universität Potsdam

Humanwissenschaftliche Reihe ; 405

ISSN 1866-8364

http://nbn-resolving.de/urn:nbn:de:kobv:517-opus4-405136 



\title{
Adult Attachment Styles, Destructive Conflict Resolution, and the Experience of Intimate Partner Violence
}

\section{Helena Bonache,' Rosaura Gonzalez-Mendez,' and Barbara Krahé}

\begin{abstract}
Although there is ample evidence linking insecure attachment styles and intimate partner violence (IPV), little is known about the psychological processes underlying this association, especially from the victim's perspective. The present study examined how attachment styles relate to the experience of sexual and psychological abuse, directly or indirectly through destructive conflict resolution strategies, both self-reported and attributed to their opposite-sex romantic partner. In an online survey, 216 Spanish undergraduates completed measures of adult attachment style, engagement and withdrawal conflict resolution styles shown by self and partner, and victimization by an intimate partner in the form of sexual coercion and psychological abuse. As predicted, anxious and avoidant attachment styles were directly related to both forms of victimization. Also, an indirect path from anxious attachment to IPV victimization was detected via destructive conflict resolution strategies. Specifically, anxiously attached participants reported a higher use of conflict engagement by themselves and by their partners. In addition, engagement reported by the self and perceived in
\end{abstract}

\footnotetext{
'Universidad de La Laguna, Spain

${ }^{2}$ University of Potsdam, Germany

\section{Corresponding Author:}

Helena Bonache, Universidad de La Laguna, Campus de Guajara, Facultad de Psicología, 38205 La Laguna, Tenerife, La Laguna 38205, Spain.

Email: helena.bonache.00@ull.edu.es
} 
the partner was linked to an increased probability of experiencing sexual coercion and psychological abuse. Avoidant attachment was linked to higher withdrawal in conflict situations, but the paths from withdrawal to perceived partner engagement, sexual coercion, and psychological abuse were non-significant. No gender differences in the associations were found. The discussion highlights the role of anxious attachment in understanding escalating patterns of destructive conflict resolution strategies, which may increase the vulnerability to IPV victimization.

\section{Keywords}

attachment styles, conflict resolution, intimate partner violence, psychological abuse, sexual coercion

\section{Introduction}

A growing body of research indicates high prevalence rates of different forms of intimate partner violence (IPV) among college students, with a wealth of negative consequences on health and well-being (Kaukinen, 2014; Shorey, Febres, Brasfield, \& Stuart, 2012). This has led researchers to investigate the factors that enable a better understanding of violence in intimate relationships. In this line of research, attachment theory has been proposed as a useful framework for analyzing psychological abuse (Doumas, Pearson, Elgin, \& McKinley, 2008) and sexual coercion (Sutton \& Simons, 2015), two forms of violence with high prevalence rates among college students (Krahé \& Berger, 2013; Muñoz-Rivas, Graña, O’Leary, \& González, 2009). However, the psychological processes underlying the association between attachment style and IPV are still not well understood (Péloquin, Lafontaine, \& Brassard, 2011). One potential mechanism is couples' conflict resolution strategies, which have been related repeatedly to both adult attachment styles and differential vulnerability to IPV victimization. Specifically, insecure attachment has been linked to the use of negative communication patterns in handling conflicts in romantic relationships (Fowler \& Dillow, 2011; Sierau \& Herzberg, 2012). In some relationships, these patterns have also been associated with different forms of IPV (Katz \& Myhr, 2008; Salwen \& O'Leary, 2013). The majority of these studies have focused on the link between attachment style and IPV perpetration and have identified insecure attachment as a risk factor for abusive behavior toward an intimate partner among both men and women (e.g., Bélanger, Mathieu, Dugal, \& Courchesne, 2015; Dutton, 2011).

A small number of studies have found that insecure attachment styles are also related to IPV victimization (e.g., Bookwala, 2002; Henderson, 
Bartholomew, Trinke, \& Kwong, 2005; Higginbotham, Ketring, Hibbert, Wright, \& Guarino, 2007; McKeown, 2014). To extend this limited body of research, the present study examined the role of conflict resolution styles (self-reported and attributed to the partner) as a variable underlying the relationship between adult attachment styles and vulnerability to two common forms of victimization in a sample of Spanish college students: psychological abuse and sexual coercion. Psychological abuse is composed of acts intended to humiliate, intimidate, threaten, dominate, or control the partner but do not include physical aggression (Shorey et al., 2012). Verbally coercive sexual strategies, such as insistence or emotional blackmail, are also common in romantic relationships (Katz \& Myhr, 2008).

Based on previous research, we investigated the proposition that insecure attachment is a vulnerability factor for IPV victimization. Research has shown both avoidantly attached and anxiously attached women to be more vulnerable to experiencing sexual victimization compared with securely attached women (Gentzler \& Kerns, 2004), albeit through different pathways. Continued attempts by avoidantly attached individuals to avoid conflicts may contribute to undermining their confidence in their ability to prevent their partner's abusive behavior. Moreover, anxiously attached individuals may be more likely to give in to unwanted sexual contacts because they need sexual intimacy for reassurance and are afraid of eliciting negative affect in their partner. They may also be less able to reject psychological abuse for fear of alienating the partner. These considerations suggest that attachment style may be implicated in IPV victimization by facilitating patterns of communication that increases the probability of abuse by an aggressive partner. Insecure attachment not only shapes people's own communication strategies in conflict situation, but also their perception of the partner's conflict resolution strategies, so that, for instance, anxiously attached individuals are more likely to perceive their partner as withdrawing in conflict situations.

\section{Attachment Styles and Conflict Resolution}

From an attachment perspective, it is assumed that experiences in early close relationships lead to the formation of internal working models that influence cognition, affect, and behavior in relationships with later attachment figures (Simpson, Rholes, \& Winterheld, 2010). These working models are considered to be expressed as different attachment styles. While securely attached individuals (i.e., low attachment anxiety and avoidance) tend to show independence and comfort with intimacy, insecurely attached people tend to display a variety of dysfunctional thoughts and feelings about the self and others (Sierau \& Herzberg, 2012). Specifically, 
individuals high on anxious attachment show a strong need for intimacy and fear of being rejected by their partners, whereas highly avoidant persons tend to show emotional detachment and self-sufficiency. Thus, dysfunctional thoughts and behaviors associated with these styles often favor the use of destructive conflict resolution strategies by both partners (Fowler \& Dillow, 2011; Sierau \& Herzberg, 2012). Hence, depending on adult attachment style, conflicts may be resolved, remain unresolved, or get worse. It is important to note that in the present context, conflict styles are qualified as "destructive" in the sense of having the potential to destroy the relationship. This does not rule out the possibility that engagement or withdrawal may be functional for the victim in an abusive relationship. For example, withdrawal may be a more successful strategy than attempts at resolving a conflict through negotiation in relationship in which one partner coercively controls the other, as conceptualized in the construct of "intimate terrorism" (Johnson, 2006; Straus \& Gozjolko, 2014).

Secure attachment has been associated with positive conflict resolution styles (Creasey \& Ladd, 2005), whereas anxious attachment has been consistently linked to withdrawal strategies, such as refusing to discuss the issue further ignoring the partner, as well as to conflict engagement behaviors, such as personal attacks and losing control (Collins, Ford, Guichard, \& Allard, 2006; Sierau \& Herzberg, 2012). Specifically, anxiously attached individuals seem to fluctuate between withdrawal and active engagement through intrusive behaviors and criticisms; the former strategy being driven by their fear of rejection and the latter by trying to satisfy the needs for proximity, support, and love (Fowler \& Dillow, 2011).

Moreover, individuals who endorse conflict engagement responses tend to see their relationship in a more negative light and make more negative interpretations of their partner's behaviors (Honeycutt, Sheldon, Pence, \& Hatcher, 2015), especially when they score high in attachment anxiety (Collins et al., 2006). Thus, anxiously attached individuals may interpret their partner's transgressions either as hostility or withdrawal (Collins et al., 2006; Gallo \& Smith, 2001). Likewise, higher levels of attachment anxiety have been related to the escalation of conflicts (Campbell, Simpson, Boldry, \& Kashy, 2005). In this sense, anxious attachment seems to be related to both forms of destructive conflict strategies.

By contrast, an avoidant attachment style has been more frequently associated with evasive communication, avoiding disagreements, and getting away from conflicts (Fowler \& Dillow, 2011). Therefore, it seems reasonable to expect that while avoidantly attached individuals keep silent or use delaying tactics, their partners tend to criticize, demand changes, and engage in conflict. 


\section{Conflict Resolution Styles and IPV}

Given that conflicts are an unavoidable feature of close relationships, a large body of research has examined how individuals' strategies for managing these conflicts relate to the functioning of the couple (McGinn, McFarland, $\&$ Christensen, 2009). According to this body of research, the use of a constructive style promotes positive and satisfying relationships, which generate more open discussions and compromise strategies in conflict situations (Cornelius, Alessi, \& Shorey, 2007). By contrast, destructive conflict resolution strategies, such as conflict engagement and withdrawal, predicted poor satisfaction and subjective well-being in couples, increasing the likelihood that conflicts will escalate (Siffert \& Schwarz, 2011).

Engagement/withdrawal is one destructive communication pattern that has received considerable attention. While one partner criticizes, annoys, and demands, the other partner evades the conflict through silence, changing the topic, or passively disengaging from the interaction (Christensen \& Heavey, 1990). Although early studies found that the most common pattern was for women to actively engage in conflict and men to withdraw, more recent research has suggested that engaging or withdrawing depends not so much on gender, but on who generates the conflict topic (Eldridge, Sevier, Jones, Atkins, \& Christensen, 2007; Holley, Sturm, \& Levenson, 2010).

Although destructive conflict resolution styles have been most commonly associated with psychological abuse, they may also be linked to the perpetration of both physical aggression (Honeycutt et al., 2015) and sexual coercion (Katz \& Myhr, 2008). Moreover, research has also examined links between IPV victimization and self-reported and partner-attributed conflict resolution styles. For example, sexual coercion (Leavitt \& Willoughby, 2015; Salwen \& O'Leary, 2013) and psychological abuse victimization (Hellmuth, Jaquier, Overstreet, Swan, \& Sullivan, 2014) have been found to be related to selfreported conflict engagement, withdrawal, and miscommunication. Moreover, evidence has also shown that partners' conflict engagement is strongly related to IPV victimization and perpetration (Bonache, Ramirez-Santana, \& Gonzalez-Mendez, in press; Carlson \& Jones, 2010). Victims of emotional abuse reported that their partners showed a frequent engagement communication pattern (Katz \& Myhr, 2008) and aggressors admitted showing conflict engagement behaviors (Fournier, Brassard, \& Shaver, 2011). These findings suggest that victims' attributions of partner engagement are matched by aggressors' reported engagement. By contrast, findings on withdrawal strategies do not show a consistent relation to IPV victimization. Specifically, victims of either psychological or sexual abuse did not report more withdrawal behaviors by their partners compared with non-victims, but victims of both forms of IPV did (Katz, Moore, \& May, 2008). 
Furthermore, an interrelation between conflict engagement strategies of self and partner has been found regarding psychological and sexual abuse. When both members of a couple actively engage in conflicts through making demands, annoying, and criticizing the partner, arguments may escalate toward more abusive behavior (Allison, Bartholomew, Mayseless, \& Dutton, 2008). By contrast, dyadic withdrawal patterns have remained largely unexplored, probably because it has been assumed that conflicts tend to fade away if both partners use withdrawal behaviors.

\section{Indirect Paths from Attachment to IPV via Conflict Resolution Strategies}

In male perpetrator samples, an indirect path has been found from insecure attachment to psychological abuse through the perception of destructive conflict resolution. Specifically, anxiously attached men tended to report more frequent abusive behaviors when they perceived a man-engagement/womanwithdrawal communication pattern. However, the perception of this communication pattern did not explain the relationship between avoidant attachment and IPV (Fournier et al., 2011). Although these findings are based on samples of perpetrators of IPV, the literature suggests similar relationships between insecure attachment and IPV when conflict management styles are analyzed from the victim's perspective (Higginbotham et al., 2007; Oka, Sandberg, Brandford, \& Brown, 2014). In fact, vulnerability to IPV was found to increase when both members of a couple showed insecure attachment (Allison et al., 2008; Péloquin, et al., 2011), especially when poor conflict resolution strategies were included in the analysis (Bond \& Bond, 2004).

In short, previous research and theorizing suggest an association between insecure attachment styles, conflict resolution strategies (self-reported and perceived in the partner), and IPV victimization (psychological abuse and sexual coercion). However, further analyses are required to investigate the direct and indirect links among these factors.

\section{The Current Study}

Based on the literature reviewed above, this study is aimed at better understanding the links between adult attachment style, conflict management strategies in romantic relationships, and two forms of IPV, namely psychological abuse and sexual coercion. There are several gaps in the current body of knowledge that require attention. First, only a minority of studies have examined vulnerability factors for IPV victimization (Gentzler \& Kerns, 2004; 
Higginbotham et al., 2007; Sutton \& Simons, 2015). Second, research has paid little attention to how insecurely attached individuals perceive their own and their partner's behaviors during relationship conflicts (Collins et al., 2006; Fournier et al., 2011), and how these perceptions are linked to IPV victimization (Bond \& Bond, 2004). Third, the focus has been almost exclusively on women as victims (Kuijpers, van der Knaap, \& Winkel, 2012), despite evidence that both women and men may suffer psychological abuse and sexual coercion in their romantic relationships (Allison et al., 2008; Krahé \& Berger, 2013; Péloquin et al., 2011). In addition, gender has not been found to moderate the relationship between attachment styles and IPV victimization (Henderson et al., 2005). However, whether the path from attachment styles to IPV via conflict resolution strategies varies between men and women still remains to be investigated. Fourth, although verbal sexual coercion in dating relationships is closely related to psychological abuse (Katz \& Myhr, 2008; Salwen \& O'Leary, 2013), it has been analyzed less frequently than other forms of IPV (Medina-Ariza \& Barberet, 2003).

In an effort to address these gaps in the literature and integrate prior research on IPV victimization into an unifying model, the aim of our study was twofold: (a) to analyze the direct links between attachment styles, conflict resolution patterns, and IPV victimization and (b) to examine the role of self-reported conflict resolution styles and conflict resolution styles perceived in the partner in explaining the link between insecure attachment and vulnerability to IPV victimization in the form of psychological abuse and sexual coercion. Male and female college students from Spain were asked about withdrawal and engagement behaviors shown during conflicts in their relationships both by themselves and their partner. In addition, their attachment styles and their experience of sexual coercion and psychological abuse were measured.

For the first goal, the following hypotheses were specified:

Hypothesis 1: Anxious (H1a) and avoidant (H1b) attachment styles will be significantly and positively related to both forms of IPV victimization (psychological abuse and sexual coercion).

Hypothesis 2: While anxious attachment will relate positively to selfreported conflict engagement (H2a) and withdrawal (H2b), avoidant attachment will only be related to higher self-reported withdrawal $(\mathrm{H} 2 \mathrm{c})$.

Hypothesis 3: While anxiously attached individuals will attribute more withdrawal (H3a) and conflict engagement $(\mathrm{H} 3 \mathrm{~b})$ behaviors to their partners, those high in attachment avoidance will attribute more engagement to their partners $(\mathrm{H} 3 \mathrm{c})$. 
Hypothesis 4: Regarding the engagement/withdrawal pattern, selfreported conflict engagement will be positively related to perceived partner withdrawal (H4a), and self-reported withdrawal will be related to partner-attributed conflict engagement (H4b). Given the proposed escalation pattern, it is expected that conflict engagement strategies of self and partner are significant and positively associated $(\mathrm{H} 4 \mathrm{c})$.

Hypothesis 5: Conflict engagement behaviors of self (H5a) and partner (H5b), as well as withdrawal strategies of self (H5c), will be significant and positively related to both forms of IPV victimization.

For the second objective addressing the indirect paths from attachment styles to victimization, the following hypotheses were proposed:

Hypothesis 6: Anxious attachment will be indirectly related to both forms of IPV victimization through conflict engagement behaviors of both self and partner.

Hypothesis 7: Anxious attachment (H7a) and avoidant attachment (H7b) will be indirectly related to both forms of IPV victimization through selfreported withdrawal and conflict engagement attributed to the partner.

The role of gender in the proposed relationships was also analyzed. However, no specific hypotheses were put forward because no previous studies have examined male victimization in relation to adult attachment styles and conflict communication patterns.

\section{Method}

\section{Participants and Procedure}

A total of 216 undergraduates from Spain (76.4\% women), sexually oriented to persons of the opposite sex, participated in the study. The mean age was 21.40 years $(S D=3.63$, range $=17-44)$. More than half of the participants $(61.6 \%)$ were in a steady relationship at the time of the study, and all of them indicated that they had been in a romantic relationship in the past. On average, the current dating relationship had lasted for 18.9 months $(S D=27.96)$, and the participants not currently in a relationship had been without a steady partner for 5.99 months $(S D=11.62)$ on average.

Participants were recruited in classrooms, and those who volunteered to take part were informed about the main characteristics of the study. Data collection was conducted online and anonymity of the responses and confidentiality of data was assured. 


\section{Instruments}

Adult attachment style. To measure attachment style, we used the Spanish adaptation (Fernández-Fuertes, Orgaz, Fuertes, \& Carcedo, 2011) of the Experiences in Close Relationships-Revised Scale (ECR-R; Fraley, Waller, $\&$ Brennan, 2000). This 18-item measure comprises nine items assessing anxiety about abandonment $(\alpha=.86$; example item: "I often wish that my partner's feelings for me were as strong as my feelings for him or her") and nine items assessing avoidance of intimacy $(\alpha=.88$; example item: "I get uncomfortable when a romantic partner wants to get very close"). The response scale ranged from 1 (strongly disagree) to 7 (strongly agree).

Conflict resolution strategies. The Conflict Resolution Styles Inventory (CRSI; Kurdek, 1994) used to measure conflict resolution strategies consists of 16 items, which are grouped into four categories: Conflict Engagement, Positive Problem Solving, Withdrawal, and Compliance. Participants indicated how frequently $(1=$ never; $5=$ always $)$ they had used each of the styles when having an argument or disagreement with their partner (CRSI-Self). In a second part, they rated the same items for their partner's behavior (CRSI-Partner). For this study, only Conflict Engagement (e.g., "Exploring and getting out of control") and Withdrawal (e.g., "Tuning the other person out") were used as both self ratings and perceived partner ratings. A confirmatory factor analysis (CFA) of the Spanish version of both subscales indicated a clear two-factor structure $\left(\chi^{2} / d f=1.58\right.$, root mean square error of approximation [RMSEA] $=$ .052 , comparative fit index $[\mathrm{CFI}]=.96$ ), the loadings of the items on their respective factors ranged from .35 to .86 . Cronbach's alphas for the present sample (self and perceived in partner, respectively) were . 77 and .84 for conflict engagement, and .73 and .81 for withdrawal. These coefficients are consistent with prior research (Kurdek, 1994; Sierau \& Herzberg, 2012; Siffert \& Schwarz, 2011).

Psychological abuse victimization. Psychological abuse victimization was measured with the Spanish adaptation of the Subtle and Overt Psychological Abuse Scale (SOPAS; Marshall, 2001) by Buesa and Calvete (2011). Respondents reported how often $(0=$ never to $5=$ many times $)$ their partner had used each of 34 behaviors in a loving, joking, or serious manner in the past year, such as "say something that makes you worry about whether you're going crazy," and "say or do something that makes you feel unloved or unlovable." All items were summed to create a total psychological abuse score. The scale had an internal consistency of .97, which is similar to other studies including both men and women (Rauer, Kelly, Buckhalt, \& El-Sheikh, 2010). 
Sexual coercion victimization. To assess sexual coercion victimization, a scale consisting of 15 items was used (Hernández \& Gonzalez-Mendez, 2009). Participants were asked to report how often their partner had shown each of 15 behaviors when they refused his or her sexual advances. It includes items such as "He/she tells me that with his/her previous partners this didn't happen," "He/she questions my femininity/ masculinity," or "He/she stops being in love with me." Answers were given on an 11-point scale $(0=$ never; $10=$ all the time). Five of the items were not considered for this analysis: two provided non-coercive alternatives (e.g., "He/she completely understands and does not insist more"); one made reference to alcohol or drugs use (e.g., "He/she encourages me to drink alcohol or drugs to overcome my resistance"), which is less present in romantic relationships (Abbey, Zawacki, Buck, Clinton, \& McAuslan, 2004); and two referred to sexual violence (e.g., "He/she forces me to have sex with penetration"), which is different from sexual coercion (Koss et al., 2007; Struckman-Johnson, Struckman-Johnson, $\&$ Anderson, 2003). A composite score was calculated across the remaining 10 items, with higher scores indicating more frequent victimization. The good internal consistency of $\alpha=.89$ was consistent with prior research (Hernández \& Gonzalez-Mendez, 2009).

Socio-demographic variables. Participants completed a demographic information section that included questions on gender, age, sexual orientation, and number and length of relationships.

\section{Results}

\section{Descriptive Statistics and Zero-Order Correlations}

A multivariate analysis of variance was conducted, using participant gender as the independent variable, and sexual coercion, psychological abuse, selfreported and perceived conflict engagement and withdrawal, and anxious as well as avoidant attachment as dependent variables. A significant multivariate effect of gender was found, $F(8,207)=3.34, p<.001, \eta_{\mathrm{p}}^{2}=.11$, and four of the univariate effects were significant. Specifically, men scored higher than did women on sexual victimization, $F(1,214)=7.92, p<.01, \eta_{\mathrm{p}}^{2}=.04$, psychological abuse victimization, $F(1,214)=5.77, p<.05, \eta_{\mathrm{p}}^{2}=.03$, and perception of partner withdrawal strategies in conflict situations, $F(1,214)=$ $5.22, p<.05, \eta_{\mathrm{p}}^{2}=.02$. Women reported more withdrawal behaviors of self than did men, $F(1,214)=5.10, p<.05, \eta_{\mathrm{p}}^{2}=.02$. The latter two findings indicate that men perceived their partners as moving away from conflicts, and correspondingly women perceive themselves as using more withdrawal 
strategies. No gender differences were found in anxious or avoidant attachment, neither in self-reported or perceived partner conflict engagement strategies.

In a second multivariate analysis of variance (MANOVA), we analyzed differences in anxious and avoidant attachment styles between participants who were single or in a relationship. The multivariate effect of relationship status was significant, $F(2,223)=18.59, p<.001, \eta_{\mathrm{p}}^{2}=.14$, and the univariate effects for both anxious attachment, $F(1,214)=13.28, p<.001, \eta_{\mathrm{p}}^{2}=.06$, and avoidant attachment, $F(1,214)=28.68, p<.001, \eta_{\mathrm{p}}^{2}=.12$, were also significant. Participants who were in a relationship at the time of the study had lower scores than those not in a relationship on attachment anxiety, $M=$ $3.24(S D=1.22)$ versus $M=3.89(S D=1.36)$, and on attachment avoidance, $M=1.97(S D=1.00)$ versus $M=2.74(S D=1.06)$.

Besides the means and standard deviations, Table 1 also shows the zeroorder correlations between all variables, separately for women and men. In both gender groups, the two forms of IPV victimization showed positive correlations with all study variables (i.e., higher levels of anxious and avoidant attachment and more destructive conflict strategies of self and partner). The only exception was a non-significant correlation between self-reported conflict withdrawal and sexual coercion in men.

Among women, self-reported and perceived partner conflict engagement were significantly correlated, as were self-reported and perceived partner withdrawal. In addition, self-reported engagement was significantly correlated with partner withdrawal, and self-reported withdrawal correlated significantly with perceived partner engagement. These demand/withdrawal communication patterns were not found in men, but male participants showed a significant correlation between self-reported and perceived partner conflict engagement.

In both gender groups, anxious attachment correlated significantly with both destructive conflict styles, self-reported and perceived in the partner. Correlations between avoidant attachment and destructive conflict resolution styles were significant only among women. Among men, only the correlation between avoidance and self-reported withdrawal was significant.

\section{Paths from Attachment Style to IPV Victimization}

The role of dyadic conflict resolution strategies in the relationship between insecure attachment and psychological and sexual victimization were examined through structural equation modeling, using the Mplus 7.1 software (Muthén \& Muthén, 1998-2012). The following indicators of fit were used: the chi-square, the CFI (cut-off criterion of .95 or higher), RMSEA (values 


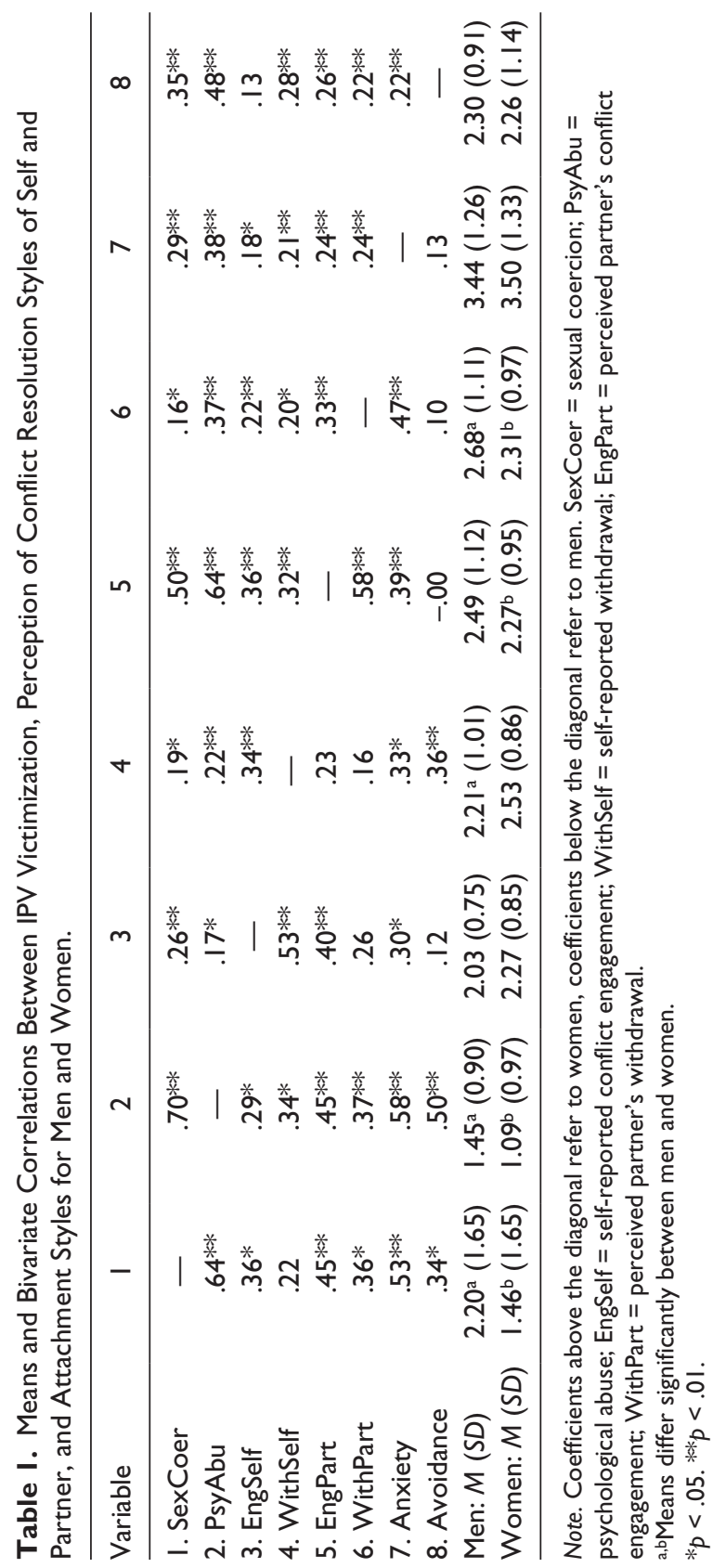




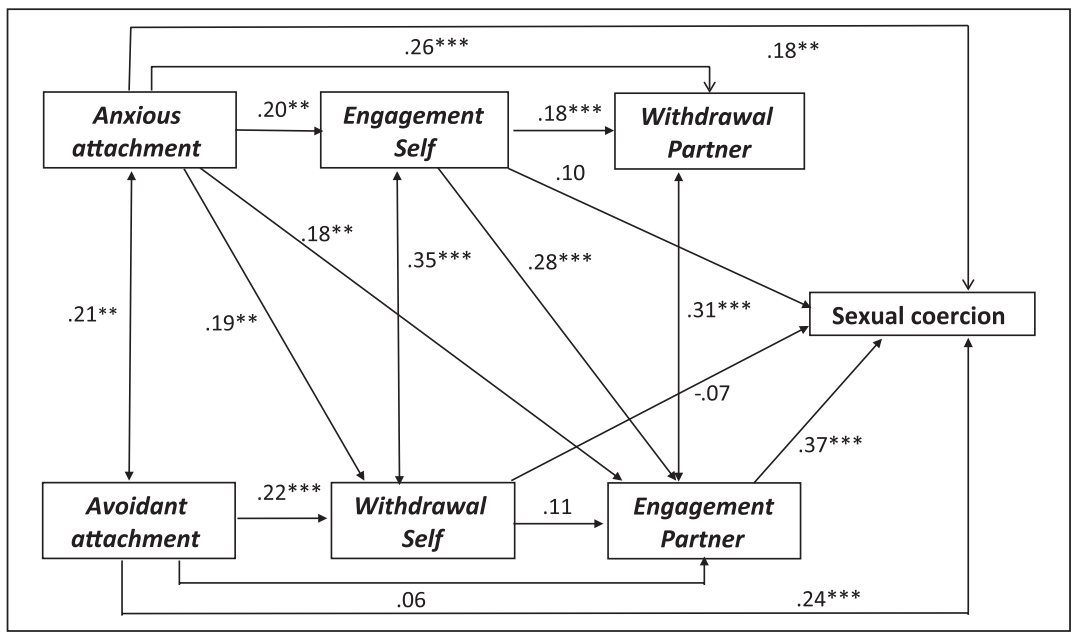

Figure I. Paths from adult attachment styles to sexual coercion through the perception of conflict resolution strategies of self and partner.

between .05 and less than .08 indicate an acceptable fit), and standardized root mean square residual (SRMR, values equal or less than .08 indicate a good fit; see Schreiber, Nora, Stage, Barlow, \& King, 2006).

We tested the hypothesized links between attachment styles, destructive conflict resolution strategies of self and partner, and psychological abuse as well as sexual coercion victimization in a single model. However, for the sake of clarity, we present the paths for the two forms of IPV victimization separately in Figure 1 (sexual coercion) and Figure 2 (psychological abuse). The aggregate scores on each measure were used as manifest variables. All direct and indirect paths were tested by bootstrapping $(10,000)$. We first specified a model in which all paths were constrained to be equal for the two gender groups. This constrained model showed a good fit with the data, $\chi^{2}(d f=34)=$ 52.83, $p=.02$, RMSEA $=.07,95 \%$ confidence interval $(\mathrm{CI})=[.03, .11]$, $\mathrm{CFI}=.96 ; \mathrm{SRMR}=.07$. Next, we estimated a model in which all paths were freely estimated for each gender group, $\chi^{2}(d f=11)=18.08, p=.08$, RMSEA $=.08,95 \% \mathrm{CI}=[.00, .14], \mathrm{CFI}=.99 ; \mathrm{SRMR}=.04$. A comparison of the two models showed that the unconstrained model did not fit the data significantly better than the constrained model, diff $\chi^{2}(d f=23)=34.95, p=.06$. Therefore, a model for the whole sample was estimated. Gender was included as a predictor for all variables in the model to account for the gender main effects, as indicated by the MANOVA. This model showed a good fit with the data, $\chi^{2}(d f=5)=10.51, p=.06$, RMSEA $=.07,95 \% \mathrm{CI}=[.00, .13], \mathrm{CFI}=.99$, 


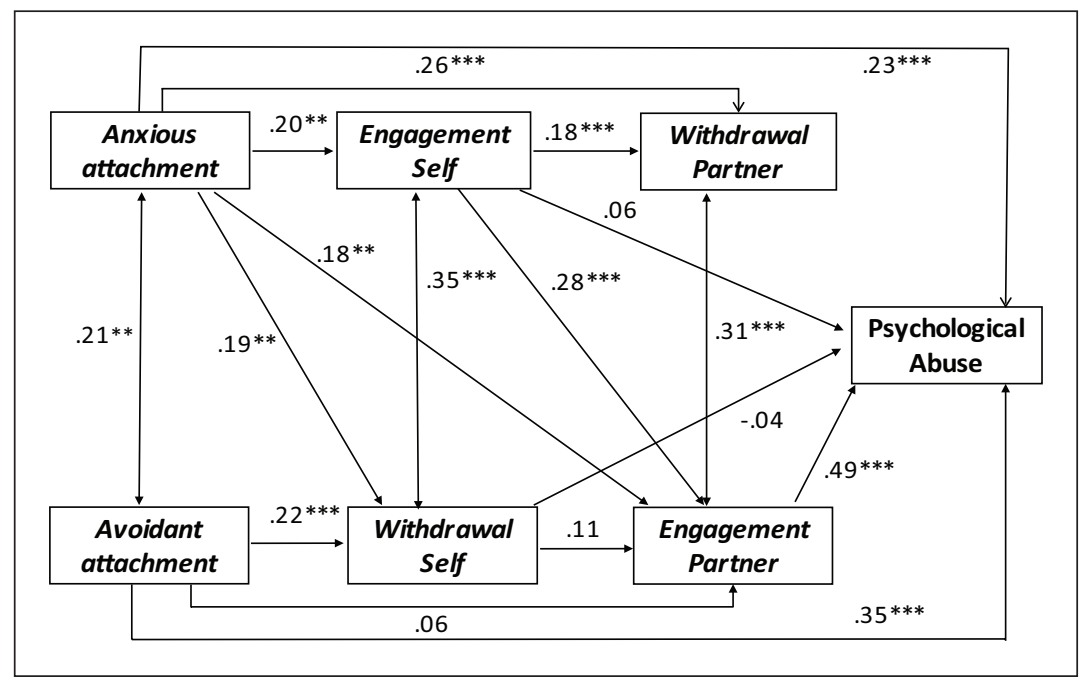

Figure 2. Paths from adult attachment style to psychological abuse through the perception of conflict resolution strategies of self and partner.

SRMR $=.029$, and was therefore adopted as the final model. The path coefficients postulated in our hypotheses are presented in Figure 1 for sexual coercion and Figure 2 for psychological abuse as outcome variables.

All proposed direct paths between insecure attachment styles and both forms of victimization were significant, supporting Hypothesis 1. The direct paths from anxious attachment to self-reported engagement and withdrawal strategies were also significant, as was the path from avoid attachment to self-reported withdrawal behaviors, supporting Hypothesis 2. Regarding the partner's conflict resolution styles, anxious attachment was associated with both types of destructive conflict strategies perceived from the partner, supporting Hypotheses 3a and 3b. Contrary to what we expected in Hypothesis $3 \mathrm{c}$, the association between avoid attachment and the perception of the partner's conflict engagement was not significant.

Confirming the predicted engagement/withdrawal pattern, self-reported conflict engagement strategies were significantly linked to partner's withdrawal behaviors. However, self-reported withdrawal was not related to perceived conflict engagement by the partner. In combination, these findings support Hypothesis $4 \mathrm{a}$, but not Hypothesis 4b. In line with the proposed escalation pattern, a significant path was found from self-reported conflict engagement to conflict engagement strategies attributed to the partner, consistent with Hypothesis 4c. 
As expected, the higher the partner's conflict engagement was perceived to be, the higher participants' scores on the sexual coercion and psychological abuse victimization measures, supporting Hypothesis $5 \mathrm{~b}$. However, the links between the self-reported strategies and both forms of victimization predicted in Hypothesis 5a were not supported. Neither self-reported conflict engagement nor self-reported withdrawal were significantly linked to psychological abuse and sexual coercion.

The indirect paths from attachment styles to IPV victimization were tested using the bootstrapping approach. In line with Hypothesis 6, significant indirect paths were found from anxious attachment via self-reported conflict engagement and perceived partner conflict engagement to both sexual coercion $(\beta=.02, p<.05,95 \% \mathrm{CI}=[.002, .075])$ and psychological abuse $(\beta=$ $.03, p<.05,95 \% \mathrm{CI}=[.001, .054])$. Contrary to Hypothesis $7 \mathrm{a}$, the indirect paths from anxious attachment via self-reported withdrawal and partner's conflict engagement to sexual coercion $(\beta=.01)$ and psychological abuse $(\beta=.01)$ were not significant. No significant indirect paths from avoidant attachment to the two outcome variables were found (sexual coercion: $\beta=$ .01 ; psychological abuse: $\beta=.01$ ), failing to support Hypothesis $7 \mathrm{~b}$. A final significant result referred to the indirect paths from self-reported conflict engagement via perceived partner engagement to sexual coercion $(\beta=.10$, $p<.05,95 \% \mathrm{CI}=[.05, .43])$ and to psychological abuse $(\beta=.14, p<.05$, $95 \% \mathrm{CI}=[.05, .31])$. These paths are consistent with the escalation pattern proposed in Hypothesis 4c.

Finally, to account for the differences in attachment styles between participants who were single and in a relationship at the time of the study, we conducted a set of multigroup analyses in which relationship status was used as the grouping variable and gender was included as a covariate. The model constraining all paths to be equal for the two relationship groups showed a good fit with the data, $\chi^{2}(d f=42)=58.87, p=.04$, RMSEA $=.06,95 \% \mathrm{CI}=$ $[.01, .10]$, CFI $=.96$, SRMR $=.08$, and did not fit worse than a model in which all path were allowed to vary, $\operatorname{diff} \chi^{2}(d f=31)=42.91, p=.09$. Thus, there is no indication that the paths from attachment styles to IPV victimization differed as a function of participants' current relationship status.

\section{Discussion}

Although research has consistently shown a link between insecure attachment and IPV (Doumas et al., 2008; Lawson \& Malnar, 2011), there is a lack of evidence about the mechanisms underlying this relationship, especially with regard to the likelihood of experiencing IPV victimization. To address this gap in the literature, the current study analyzed whether insecure attachment 
would be indirectly linked to two forms of IPV victimization, psychological abuse and sexual coercion, through conflict resolution strategies employed by individuals and perceived from their partner. The proposed links were examined in a sample of Spanish college students.

According to attachment theory, individuals perceive and experience their intimate relationships through their internal working models, which are reflected in their attachment styles (Simpson et al., 2010). Evidence has also indicated that insecurely attached individuals are more likely to use destructive conflict resolution strategies (Fowler \& Dillow, 2011; Sierau \& Herzberg, 2012). Thus, it was hypothesized that anxious attachment would be associated with greater self-reported conflict engagement and withdrawal, whereas avoidant attachment would be more likely to be associated with self-reported withdrawal.

The results of this study support these predictions, and they are consistent with attachment theoretical considerations. Individuals high in attachment avoidance tend to use more evasive communication strategies, which can be interpreted as an intent to stay away from dependency and closeness (Beck, Pietromonaco, DeVito, Powers, \& Boyle, 2014; Fowler \& Dillow, 2011). Moreover, those high in attachment anxiety, characterized by the fear of rejection, may avoid discussing conflict topics, while trying to satisfy their needs for proximity, support, and love through conflict engagement (Collins et al., 2006; Gallo \& Smith, 2001). Consistent with this pattern, communication difficulties are among the most frequently endorsed motives among young couples involved in less severe violence (Carlson \& Jones, 2010).

With regard to gender, our analysis showed that the proposed pathways from attachment styles to victimization did not vary between men and women. This finding is consistent with earlier research including both female and male participants (Henderson et al., 2005). However, given the limited number of studies including both men and women as victims of IPV, more research is needed to conclusively determine the role of gender in the relationship between attachment styles, conflict resolution, and victimization.

In addition, insecurely attached individuals tend to interpret their partner's behaviors in ways that are consistent with their internal working models (Campbell et al., 2005; Gallo \& Smith, 2001). As expected, the more anxiously attached participants were, the more likely they were to interpret their partners' conflict strategies in a more negative way, perceiving them to show more conflict engagement and withdrawal behaviors. In contrast, avoidant attachment was not associated with the perception of partner conflict engagement strategies. These findings are consistent with prior research which showed that highly avoidant individuals tend to blame themselves for their partner's transgressions (Collins et al., 2006), instead of perceiving their 
partner behaving in a proactive way during marital conflicts (Allison et al., 2008; Beck et al., 2014). These biased perceptions may help to reduce negative affect by dismissing the importance of arguments. At the same time, they reinforce the internal working models of avoidant attachment, upholding distance and independence in romantic relationships. It is worth noting that although both attachment styles and conflict resolution patterns rely on internal working models of relationships and may show some overlap at the behavioral level, the associations found in our study were relatively small, which attests to the conceptual distinction between these constructs.

Although the engagement/withdrawal communication pattern has been strongly supported in previous research (Eldridge et al., 2007; Holley et al., 2010), our findings only confirmed the association between self-reported engagement and partner's withdrawal behaviors. The reverse communication pattern from self-reported withdrawal to partner engagement was not significant, which suggests two different but compatible explanations. One is that individuals who adopt withdrawal strategies to try to evade conflicts and prevent arguments may be less attentive to their partner's behavior. In addition, their own conflict issues may have been more salient to participants than their partner's, leading them to perceive their active conflict engagement to be more pronounced than their partner's while being less aware of their own than their partner's withdrawal behavior. This interpretation is consistent with findings from McGinn et al. (2009), who studied demand/withdrawal patterns in couples and found that the pattern of self-demand/partner-withdraw was more pronounced when discussing their own as opposed to their partner's conflict issues.

Even though the design used in this study is cross-sectional, the results also seem to support the conflict escalation pattern among couples. Consistent with prior research (Katz \& Myhr, 2008; Leavitt \& Willoughby, 2015), the perception of the partner's conflict engagement was linked to sexual coercion and psychological abuse victimization, whereas self-reported withdrawal and engagement was not associated with either form of victimization. However, perceiving conflict engagement in partners during disagreement was also related to the self-reported use of this strategy, suggesting an escalation of conflicts.

The second purpose of this study was to examine the indirect relationships between attachment styles and both forms of victimization through conflict resolution strategies shown by the self and attributed to the partner. Our results showed that only anxious attachment was indirectly related to IPV through conflict engagement, whereas no indirect paths were found for avoidant attachment. Past research found that male perpetrators who are high in attachment anxiety tend to behave more aggressively when they report 
more conflict engagement by themselves and perceive withdrawal by the partner, but no parallel pattern was found for avoidant attachment (Fournier et al., 2011). The present study failed to support a complementary path from the victim's perspective from self-reported withdrawal to perceived partner engagement. As noted above, this may be due to the possibility that thinking about their own conflict issues may have made the self-demand/partner withdrawal pattern more salient than the self-withdrawal/partner engagement pattern (McGinn et al., 2009).

Although the findings are largely consistent with our hypotheses, several limitations of the study must be mentioned. First, the sample was limited to college students, which does not allow for the generalization of the results to other young adult populations. Second, our measure of IPV was limited to psychological abuse and sexual coercion and it did not include physical abuse. Although there is some evidence that emotional abuse has a more negative impact on victims (Weston, 2008), whether attachment style is differentially linked to physical as compared with psychological abuse or sexual coercion remains to be conclusively established. Therefore, it would be necessary to test the model among adult couples involved in physical violence. A third limitation of this study is its cross-sectional design, which makes it impossible to establish the direction of the identified links. A longitudinal design would allow us to better understand interrelations between adult attachment styles, perception of conflict resolution strategies, and IPV victimization. For example, although conceptually attachment styles are considered to be relatively stable dispositional constructs, Weston (2008) found changes toward more avoidant and anxious attachment in a longitudinal study with women who had experienced emotional abuse. Therefore, further research is needed to examine the causal impact of IPV on adult attachment styles.

Finally, the data were obtained only from one of the partners and this may have introduced a bias in the reported partner behavior. However, studies which include both self-reported and observational data suggest that partners are valuable informants on the conflict resolution behavior of both partners within a dyad (Siffert \& Schwarz, 2011). Nonetheless, collecting data independently from both partners would be an important task for future research.

The findings from this study have implications for diversity by providing evidence from a sample of college students from Spain. The findings link up with results found in the United States, Canada, and Germany. They suggest that the associations between attachment style conflict resolution styles and vulnerability to IPV victimization apply to both gender groups, adding to a small but growing body of international research that places the victimization experiences of men on the agenda of IPV research (e.g., Chan, Straus, Brownridge, Tiwari, \& Leung, 2008). 
In summary, the results supported the proposition that the experience of psychological abuse and sexual coercion is linked to insecure attachment, especially when anxiously attached victims perceive a communication pattern that may give rise to the escalation of conflicts. Identifying vulnerabilities in victims of IPV does not imply victim blaming (Hamby \& Grych, 2016): on the contrary,it is beneficial to the development of prevention measures. Just like constructive conflict resolution strategies are skills that need to be strengthened to prevent violence in romantic relationships (De La Rue, Polanin, Espelage, \& Pigott, 2014), promoting working models of secure attachment might reduce destructive patterns of interacting in conflict situations and improve communication styles among intimate partners.

\section{Declaration of Conflicting Interests}

The author(s) declared no potential conflicts of interest with respect to the research, authorship, and/or publication of this article.

\section{Funding}

The author(s) received no financial support for the research, authorship, and/or publication of this article.

\section{References}

Abbey, A., Zawacki, T., Buck, P. O., Clinton, A. M., \& McAuslan, P. (2004). Sexual assault and alcohol consumption: What do we know about their relationship and what types of research are still needed? Aggression and Violent Behavior, 9, 271-303.

Allison, C. J., Bartholomew, K., Mayseless, O., \& Dutton, D. G. (2008). Love as a battlefield attachment and relationship dynamics in couples identified for male partner violence. Journal of Family Issues, 29, 125-150.

Beck, L. A., Pietromonaco, P. R., DeVito, C. C., Powers, S. I., \& Boyle, A. M. (2014). Congruence between spouses' perception and observers' ratings of responsiveness: The role of attachment avoidance. Personality and Social Psychology Bulletin, 40, 164-174.

Bélanger, C., Mathieu, C., Dugal, C., \& Courchesne, C. (2015). The impact of attachment on intimate partner violence perpetrated by women. Journal of Family Therapy, 43, 441-453.

Bonache, H., Ramírez-Santana, G., \& Gonzalez-Mendez, R. (in press). Conflict resolution styles and teen dating violence. International Journal of Clinical and Health Psychology.

Bond, S. B., \& Bond, M. (2004). Attachment styles and violence within couples. Journal of Nervous and Mental Disease, 192, 857-863.

Bookwala, J. (2002). The role of own and perceived partner attachment in relationship aggression. Journal of Interpersonal Violence, 17, 84-100. 
Buesa, S., \& Calvete, E. (2011). Adaptation of the subtle and overt psychological abuse scale for women in clinical samples and the community. Anales de Psicología, 27, 774-782.

Campbell, L., Simpson, J. A., Boldry, J., \& Kashy, D. A. (2005). Perceptions of conflict and support in romantic relationships: The role of attachment anxiety. Journal of Personality and Social Psychology, 88, 510-531.

Carlson, R. G., \& Jones, K. D. (2010). Continuum of conflict and control: A conceptualization of intimate partner violence typologies. The Family Journal: Counseling and Therapy for Couples and Families, 18, 248-254.

Chan, K. L., Straus, M. A., Brownridge, D. A., Tiwari, A., \& Leung, W. C. (2008). Prevalence of dating partner violence and suicidal ideation among male and female university students worldwide. Journal of Midwifery \& Women's Health, 53, 529-537.

Christensen, A., \& Heavey, C. L. (1990). Gender and social structure in the demand/withdraw pattern of marital conflict. Journal of Personality and Social Psychology, 59, 73-81.

Collins, N. L., Ford, M. B., Guichard, A. C., \& Allard, L. M. (2006). Working models of attachment and attribution processes in intimate relationships. Personality and Social Bulletin, 32, 201-219.

Cornelius, T. L., Alessi, G., \& Shorey, R. C. (2007). The effectiveness of communication skills training with married couples: Does the issue discussed matter? The Family Journal, 15, 124-132.

Creasey, G., \& Ladd, A. (2005). Generalized and specific attachment representations: Unique and interactive roles in predicting conflict behaviors in close relationships. Personality and Social Psychology Bulletin, 31, 1026-1038.

De La Rue, L., Polanin, J. P., Espelage, D. L., \& Pigott, T. D. (2014). Schoolbased interventions to reduce dating and sexual violence: A systematic review. Campbell Systematic Reviews. Retrieved February from http://www.campbellcollaboration.org/lib/download/3584/De+La+Rue_Dating_Sexual_Violence_ Review.pdf

Doumas, D. M., Pearson, C. L., Elgin, J. E., \& McKinley, L. L. (2008). Adult attachment as a risk factor for intimate partner violence: The "mispairing" of partners' attachment styles. Journal of Interpersonal Violence, 23, 616-634.

Dutton, D. G. (2011). Attachment and violence: An anger born of fear. In P. R. Shaver \& M. Mikulincer (Eds.), Human aggression and violence: Causes, manifestations, and consequences (pp. 259-275). Washington, DC: American Psychological Association.

Eldridge, K. A., Sevier, M., Jones, J., Atkins, D. C., \& Christensen, A. (2007). Demand-Withdrawal communication in severely distressed, moderately distressed, and nondistressed couples: Rigidity and polarity during relationship and personal problem discussions. Journal of Family Psychology, 21, 218-226.

Fernández-Fuertes, A. A., Orgaz, B., Fuertes, A., \& Carcedo, R. (2011). Measuring romantic attachment assessment in Spanish adolescents: Validation of the short version of the Experiences in Close Relationships-Revised (ECR-R). Anales de Psicología, 27, 827-833. 
Fournier, B., Brassard, A., \& Shaver, P. (2011). Adult attachment and male aggression in couple relationships: The demand-withdrawal pattern and relationship satisfaction as mediators. Journal of Interpersonal Violence, 26, 1982-2003.

Fowler, C., \& Dillow, M. R. (2011). Attachment dimensions and the four horsemen of the apocalypse. Communication Research Reports, 28, 16-26.

Fraley, R. C., Waller, N. G., \& Brennan, K. A. (2000). An item response theory analysis of self-report measures of adult attachment. Journal of Personality and Social Psychology, 78, 350-365.

Gallo, L. C., \& Smith, T. W. (2001). Attachment style in marriage: Adjustment and responses to interaction. Journal of Social and Personal Relationships, 18, 263-289.

Gentzler, A. L., \& Kerns, K. A. (2004). Associations between insecure attachment and sexual experiences. Personal Relationships, 11, 249-265.

Hamby, S., \& Grych, J. (2016). The complex dynamics of victimization: Understanding differential vulnerability without blaming the victim. In C. A. Cuevas (Ed.), The Wiley-Blackwell handbook on the psychology of violence (pp. 66-85). Hoboken, NJ: Wiley-Blackwell.

Hellmuth, J. C., Jaquier, V., Overstreet, N., Swan, S. C., \& Sullivan, T. P. (2014). The mediating role of avoidance coping between IPV victimization, mental health, and substance abuse among women experiencing bidirectional IPV. Psychiatry Research, 15, 391-396.

Henderson, A. J., Bartholomew, K., Trinke, S. J., \& Kwong, M. J. (2005). When loving means hurting: An exploration of attachment and intimate abuse in a community sample. Journal of Family Violence, 20, 219-230.

Hernández, E., \& Gonzalez-Mendez, R. (2009). Coerción sexual, compromiso y violencia en las relaciones de pareja de los universitarios [Sexual coercion, commitment, and partner violence in college students]. Escritos de Psicología, $2,40-47$.

Higginbotham, B. J., Ketring, S. A., Hibbert, J., Wright, D. W., \& Guarino, A. (2007). Relationship religiosity, adult attachment styles, and courtship violence experienced by females. Journal of Family Violence, 22, 55-62.

Holley, S. R., Sturm, V. E., \& Levenson, R. W. (2010). Exploring the basis for gender differences in the demand-withdrawal pattern. Journal of Homosexuality, 57, 666-684.

Honeycutt, J. M., Sheldon, P., Pence, M. E., \& Hatcher, L. C. (2015). Predicting aggression, conciliation, and concurrent rumination in escalating conflict. Journal of Interpersonal Violence, 30, 133-151.

Johnson, M. P. (2006). Conflict and control: Gender symmetry and asymmetry in domestic violence. Violence Against Women, 12, 1-16.

Katz, J., Moore, J., \& May, P. (2008). Physical and sexual covictimization from dating partners. A distinct type of intimate abuse? Violence Against Women, 14, 961-980.

Katz, J., \& Myhr, L. (2008). Perceived conflict patterns and relationship quality associated with verbal sexual coercion by male dating partners. Journal of Interpersonal Violence, 23, 798-814. 
Kaukinen, C. (2014). Dating violence among college student: The risk and protective factors. Trauma, Violence, \& Abuse, 15, 283-296.

Koss, M. P., Abbey, A., Campbell, R., Cook, S., Norris, J., Testa, M., . . White, J. (2007). Revising the SES: A collaborative process to improve assessment of sexual aggression and victimization. Psychology of Women Quarterly, 31, 357-370.

Krahé, B., \& Berger, A. (2013). Men and women as perpetrators and victims of sexual aggression in heterosexual and same-sex encounters: A study of first-year college student in Germany. Aggressive Behavior, 39, 391-404.

Kuijpers, K., van der Knaap, L. M. F., \& Winkel, F. W. (2012). Risk of revictimization of intimate partner violence: The role of attachment, anger and violent behavior of the victim. Journal of Family Violence, 27, 33-44.

Kurdek, L. A. (1994). Conflict resolution styles in gay, lesbian, heterosexual nonparent, and heterosexual parent couples. Journal of Marriage and Family, 56, 705-722.

Lawson, D. M., \& Malnar, S. G. (2011). Interpersonal problems as a mediator between attachment and intimate partner violence. Journal of Family Violence, 26, 421-430.

Leavitt, C. E., \& Willoughby, B. J. (2015). Associations between attempts at physical intimacy and relational outcomes among cohabiting and married couples. Journal of Social and Personal Relationships, 32, 241-262.

Marshall, L. (2001). Effects of men's subtle and overt psychological abuse on lowincome women. In K. D. O'Leary \& R. D. Maiuro (Eds.), Psychological abuse in violent domestic relations (pp. 153-175). New York, NY: Springer.

McGinn, M. M., McFarland, P. T., \& Christensen, A. (2009). Antecedents and consequences of demand/withdraw. Journal of Family Psychology, 23, 749-757.

McKeown, A. (2014). Attachment, personality and female perpetrators of intimate partner violence. Journal of Forensic Psychiatry \& Psychology, 25, 556-573.

Medina-Ariza, J., \& Barberet, R. (2003). Intimate partner violence in Spain: Findings from a national survey. Violence Against Women, 9, 302-322.

Muñoz-Rivas, M. J., Graña, J. L., O’Leary, K. D., \& González, M. P. (2009). Prevalence and predictors of sexual aggression in dating relationships of adolescents and young adults. Psicothema, 21, 234-240.

Muthén, L. M. P., \& Muthén, B. (1998-2012). M-plus user's guide (Version 7). Los Angeles, CA: Author.

Oka, M., Sandberg, J. G., Brandford, A. B., \& Brown, A. (2014). Insecure attachment behavior and partner violence: Incorporating couple perceptions of insecure attachment and relational aggression. Journal of Marital and Family Therapy, 40, 412-429.

Péloquin, K., Lafontaine, M. F., \& Brassard, A. (2011). A dyadic approach to the study of romantic attachment, dyadic empathy and psychological partner aggression. Journal of Social and Personal Relationships, 28, 915-942.

Rauer, A. J., Kelly, R. J., Buckhalt, J. A., \& El-Sheikh, M. (2010). Sleeping with one eye open: Marital abuse as an antecedent of poor sleep. Journal of Family Psychology, 24, 667-677. 
Salwen, J., \& O’Leary, D. K. (2013). Adjustment problems and maladaptive relational style: A mediational model of sexual coercion in intimate relationships. Journal of Interpersonal Violence, 28, 1969-1988.

Schreiber, J. B., Nora, A., Stage, F. K., Barlow, E. A., \& King, J. (2006). Reporting structural equation modeling and confirmatory factor analysis results: A review. The Journal of Education Research, 99, 323-338.

Shorey, R. C., Febres, J., Brasfield, H., \& Stuart, G. L. (2012). Male dating violence victimization and adjustment: The moderating role of coping. American Journal of Men's Health, 6, 218-228.

Sierau, S., \& Herzberg, P. H. (2012). Conflict resolution as a dyadic mediator: Considering the partner perspective on conflict resolution. European Journal of Personality, 26, 221-232.

Siffert, A., \& Schwarz, B. (2011). Spouses' demand and withdrawal during marital conflict in relation to their subjective well-being. Journal of Social and Personal Relationships, 26, 262-277.

Simpson, J. A., Rholes, W. S., \& Winterheld, H. A. (2010). Attachment working models twist memories of relationship events. Psychological Science, 21, 252-259.

Straus, M. A., \& Gozjolko, K. L. (2014). "Intimate terrorism” and gender differences in injury of dating partners by male and female university students. Journal of Family Violence, 29, 51-65.

Struckman-Johnson, C., Struckman-Johnson, D., \& Anderson, P. B. (2003). Tactics of sexual coercion: When men and women won't take no for an answer. The Journal of Sex Research, 40, 76-86.

Sutton, T. E., \& Simons, L. G. (2015). Sexual assault among college students: Family of origin hostility, attachment, and the hook-up culture as risk factors. Journal of Child and Family Studies, 24, 2827-2840.

Weston, R. (2008). Insecure attachment mediates effects of partners' emotional abuse and violence on women's relationship quality. Journal of Family Violence, 23, 483-493.

\section{Author Biographies}

Helena Bonache, MS, is a $\mathrm{PhD}$ student in the Family Intervention Program at the Universidad de La Laguna. Areas of research interest include the etiology and prevention of dating violence, both perpetration and victimization.

Rosaura Gonzalez-Mendez, $\mathrm{PhD}$, is an associate professor in the Department of Cognitive and Social Psychology, at the Universidad de La Laguna, Spain. Her research interests include the etiology and prevention of dating violence. She is currently interested in analyzing trajectories of dating violence victimization and perpetration.

Barbara Krahé, PhD, is a professor of Social Psychology in the Department of Psychology at the University of Potsdam, Germany. Her research interests lie in the area of applied social psychology, in particular aggression research and social cognition research applied to legal decision making. 